pre-defined intervals between visits with frequencies varying from daily to monthly. The remaining five made a single request before a scheduled clinic visit. The number of items requested from patients ranged from 9-48 per session. We identified three different clinical workflows: Simple (data only used during consultation, $n=5$ ), moderate (real-time alerts for providers when severe symptoms were reported, $n=4$ ) and on-demand (patient-initiated visits, $n=1$ ). Benefits of symptom reporting from each of the studies were categorised as anticipated, realized quantitative, and realized qualitative. We present summarised counts of these benefits in Figure 1. The most common anticipated benefits were better communication, changes to patient management and improved health outcomes. Most common realized benefits were detecting unrecognised problems and changes to patient management.

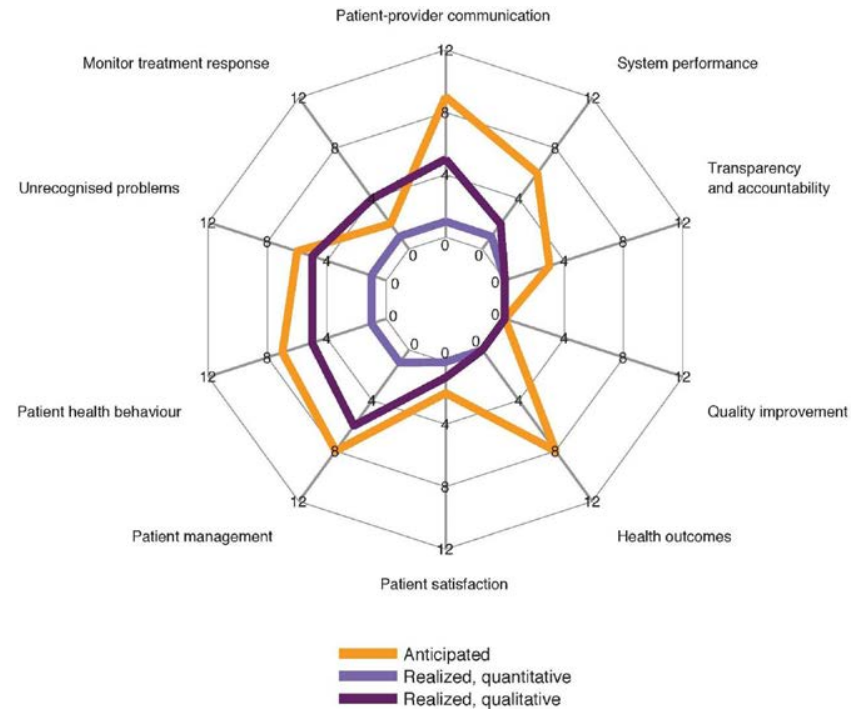

Figure 1. Summarized counts of benefits from each included study assessed against Chen et al.'s 10 outcome indicators. Categorized in anticipated (orange), realized quantitative (light purple), and realized qualitative benefits (dark purple).

Conclusion: There is growing interest and urge for integrating symptom data in the EHR and clinical care. Yet, this review has illustrated that there are limited published efforts to learn from. The heterogeneity in approaches underpins the need for a common framework. There is growing evidence from qualitative work in support of remote symptom-reporting in enabling better and patient-centred care in LTCs. The next step will be for robust, quantitative studies to provide evidence of benefits. References:

[1] Chen J, Ou L, Hollis SJ. A systematic review of the impact of routine collection of patient reported outcome measures on patients, providers and health organisations in an oncologic setting. BMC Health Serv Res. 2013 Jun 11;13:211.

Disclosure of Interests: Julie de Fonss Gandrup: None declared, Syed Mustafa Ali: None declared, Sabine van der Veer: None declared, John McBeth: None declared, William Dixon Consultant of: Bayer and Google

DOI: 10.1136/annrheumdis-2020-eular.5394

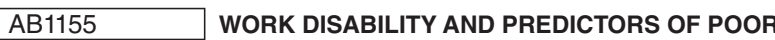 WORK OUTCOME IN PATIENTS WITH AXIAL SPONDYLOARTHRITIS}

E. Durak Ediboglu' ${ }^{1}$, D. Solmaz ${ }^{1}$, H. E. Oz ${ }^{1}$, G. Kabadayi ${ }^{1}$, H. Cinakli ${ }^{1}$, E. Otman Akad ${ }^{1}$, M. Ozmen ${ }^{1}$, S. Akar ${ }^{1}{ }^{1}$ Izmir Katip Celebi University School of Medicine, Rheumatology, Izmir, Turkey

Background: Axial spondyloarthritis (axSpA) is a chronic inflammatory disease which may lead substantial functional limitation. The disease more commonly affects men in their third decade of life. For patients with chronic disease participation in paid work may be the result of series factors like disease severity, effectiveness of the health care, availability and the type of work. Previously it was reported that ankylosing spondylitis may cause adverse work outcome. Objectives: To understand the impact of axSpA on work disability and the factors associated with poor work outcome.

Methods: A cross-sectional survey was performed among323 patients withaxSpA according to ASAS classification criteriafrom one tertiary center. In total 219 $(67.8 \%)$ patients were working age at the time study. The others were student, housewife or retired. Demographic, social and disease related characteristics were collected. Characteristic that might be associated with premature work loss were evaluated byunivariable and multivariable logistic regression analysis.
Results: Out of 219 axSpA patients (155 [71\%] r-axSpA and 64 nr-axSpA, 69\% HLA-B27 positive) who have a work at least once 47 (22\%) was either withdrawn from work $(n=35)$ or retired due to disability $(n=12)$ during median (IQR) $12(12)$ years symptom duration. Demographic and disease related characteristics of the patients with or without work diasbilitywere summarized in the table. In univariate analysis gender, smoking, education levels, the presence of peripheral arthritis, BASMI score and radiographically presence of syndesmophyte and hip involvement were found to be associated with poor work outcome. However poor work outcome were similar between $r$ - and nr-axSpA patients. In regression analy sis low education level (HR:3.4 [95\%Cl:1.4-8.6], $\mathrm{P}=0.007)$, peripheral arthritis (HR:2.7[95\%Cl:1.07-6.8], $\mathrm{P}=0.035)$, and ever smoking (HR:4.9 [95\% $\mathrm{Cl}: 1.3-18.0]$ $\mathrm{P}=0.02$ ) were independent predictors of work disability.

Conclusion: Our results suggest that there is still remarkable poor work outcome among axSpA patients and work disability might be similar in $\mathrm{r}$ - and $\mathrm{nr}$-ax$\mathrm{SpA}$. Patients who are smoker, with low education levels, and peripheral arthritis seem to be at risk for premature work loss.

Table. Demographics and diseases related characteristics of study population

\begin{tabular}{|c|c|c|c|}
\hline Variables & $\begin{array}{l}\text { All population } \\
\quad(n=219)\end{array}$ & $\begin{array}{l}\text { No work disability } \\
\qquad(\mathrm{n}=172)\end{array}$ & $\begin{array}{l}\text { Work disability } \\
\qquad(n=47)\end{array}$ \\
\hline Male, n (\%) & $161(73.5)$ & $122(70.9)$ & $39(83)$ \\
\hline Age, years* ${ }^{*}$ & & $41.5(9.4)$ & $43.1(12.4)$ \\
\hline Ever smoking, n (\%) & $155(71.4)$ & $115 / 171(67.3)$ & $40 / 46(87)$ \\
\hline Education duration $\leq 8$ years, $\mathrm{n}(\%)$ & $82 / 212(61.3)$ & $53 / 165(32.1)$ & $29 / 47(61.7)$ \\
\hline Disease duration, years & $6.7(8.3)$ & $5.5(6.3)$ & $10.7(12.6)$ \\
\hline BASDAI $^{*}$ & $4.3(2.4)$ & $4(2.3)$ & $5.3(2.6)$ \\
\hline $\mathrm{BASFI}^{*}$ & $3.4(2.8)$ & $2.9(2.5)$ & $5.4(3.0)$ \\
\hline ASDAS-CRP* & $2.8(1.2)$ & $2.7(1.1)$ & $3.3(1.4)$ \\
\hline BASMI* $^{*}$ & $2.3(2.0)$ & $2(1.8)$ & $3.5(2.4)$ \\
\hline $\mathrm{ASQOL}^{*}$ & $9(5.5)$ & $8(5.3)$ & $12(4.9)$ \\
\hline Peripheral arthritis, n (\%) & $81 / 207(39.1)$ & $54 / 163(33.1)$ & $27 / 44(61.4)$ \\
\hline Hip arthritis, $n(\%)$ & $39 / 205(19)$ & $26 / 163(16)$ & $13 / 42(31)$ \\
\hline Presence of syndesmophyte, $n(\%)$ & $92 / 164(56.1)$ & $63 / 125(50.4)$ & 29/39 (74.4) \\
\hline
\end{tabular}

* Variables presented as mean (SD).

Disclosure of Interests: None declared

DOI: 10.1136/annrheumdis-2020-eular.4227

\section{AB1156 \\ OVERVIEW OF INFLAMMATORY RHEUMATIC DISEASES AT THE EMERGENCY DEPARTMENT}

I. San ${ }^{1}$, A. Erden ${ }^{1}$, O. Küçükşahin' ${ }^{2}{ }^{1}$ Ankara City Hospital, Ankara, Turkey;

${ }^{2}$ Yıldırım Beyazıt University, Ankara, Turkey

Background: Patients with rheumatological diseases can also apply to the emergency room due to acute attacks or complications. Especially in recent years, more patients, due to the increased use of immunosuppressant drugs in treatment, have applied to emergency services due to infection. On the other hand, data on applications to emergency services for rheumatological reasons are very few.

Objectives: In this study, applications to emergency departments for inflammatory rheumatic diseases were investigated.

Methods: 2715 patients from Atatürk Training and Research Hospital Rheumatology Clinic who were followed-up with the diagnosis of inflammatory rheumatic diseases between 2014 and 2018 were included in this study. The clinical and laboratory information of the patients were achieved from the hospital file records and the hospital data bank. The patients were classified according to the 5-stage triage system (T1: resuscitation, T2: critical, T3: urgent, T4: less urgent, T5: non-urgent).

Results: $21.3 \%$ (577) of 2715 patients applied to the emergency department Among the emergency admissions, the first three diseases were; rheumatoid arthritis $19.7 \%$, ankylosing spondylitis $19.2 \%$, and familial Mediterranean fever $15.9 \%$ [Vasculitis $8.8 \%$, Behcet's disease $7.6 \%$, Gout $5.7 \%$, Systemic lupus erythematosus 3.9\%, Sjogren's Syndrome 3.6\%, Scleroderma 3.2\%, Still Disease $1.5 \%$, Polymyalgia rheumatica $0.6 \%$, others $9 \%$ ]. 343 patients $(59.5 \%)$ were discharged from the emergency department. $36.8 \%$ (212) of the patients were hospitalized in services and $3.6 \%(21)$ of them in intensive care. The first three reasons of the applications to the emergency department were: fever, malaise and fatigue in 1.150 patients (25.9\%), musculoskeletal system complaints in 2 124 patients $(21.4 \%)$ and abdominal pain in 3.89 patients $(15.4 \%)$, respectively. Vasculitis was the most common cause of hospitalization in the service in 38 patients $(17.9 \%)$, whereas scleroderma was the most common cause of hospitalization in intensive care in 7 patients (33.3\%) (table). 16 (76.1\%) of the patients followed in intensive care unit were hospitalized with the diagnosis of respiratory system diseases. Death was observed in $10(1.7 \%)$ of 577 patients. Five $(50 \%)$ of the ex-patients had scleroderma (table). $8(80 \%)$ of the deaths were related 
to rheumatological disease and occurred after being hospitalized in intensive care unit.

Conclusion: The patients with inflammatory rheumatic diseases usually apply to the emergency department with urgent or less urgent clinical pictures. Rheumatoid arthritis, one of the most common inflammatory rheumatic diseases in almost all societies, was also the most common diagnosis in our study. In the vast majority of applications, infectious causes and disease activations related to immunosuppressive treatments were in the foreground. In addition, although vasculitis is the most common reason for the in-patients in clinical service, since the most frequent in-patients in intensive care unit and death is seen in the scleroderma group; caution should be exercised in the emergency applications of patients with these two groups.

References:

[1] Rheumatology consultation in the emergency department: Annual results. RAED 2014

Table. Examination of the diagnosis of $\mathbf{2 3 3}$ patients who were hospitalized and/or died from the emergency department

\begin{tabular}{lccc}
\hline \multicolumn{1}{c}{ Parameters } & $\begin{array}{c}\text { In-patients in clinical } \\
\text { service n, (\%) }\end{array}$ & $\begin{array}{c}\text { In-patients in intensive } \\
\text { care units n, (\%) }\end{array}$ & $\begin{array}{c}\text { Died patients } \\
\mathrm{n},(\%)\end{array}$ \\
\hline Vasculitis & $38(17.9)$ & $5(23.8)$ & $1(1)$ \\
Ankylosing spondylitis & $33(15.5)$ & $3(14.2)$ & $2(20)$ \\
Rheumatoid arthritis & $31(14.6)$ & $2(9.5)$ & $5(50)$ \\
Behcet's disease & $25(11.7)$ & $1(4.7)$ & \\
Systemic lupus erythematosus & $16(7.5)$ & $7(33.3)$ & \\
Scleroderma & $10(4.7)$ & & $1(10)$ \\
Antiphospholipid syndrome & $10(4.7)$ & & $1(10)$ \\
Psoriatic arthritis & $9(4.2)$ & $1(4.7)$ & \\
Family Mediterranean fever & $8(3.7)$ & $2(9.5)$ & \\
Sjogren's Syndrome & $8(3.7)$ & & \\
Still Disease & $7(3.3)$ & & \\
Gout & $7(3.3)$ & & \\
Undifferentiated connective tissue & $7(3.3)$ & & \\
disease & $3(1.4)$ & & \\
Dermatomyositis & $212(100)$ & & \\
Total & & & \\
&
\end{tabular}

Disclosure of Interests: None declared

DOI: 10.1136/annrheumdis-2020-eular.2938

\section{AB1157 1 SEASONAL INFLUENZA VACCINATION: KNOWLEDGE AND ATTITUDES IN RHEUMATIC PATIENTS}

G. Figueroa-Parra ${ }^{1}$, L. Santoyo-Fexas ${ }^{1}$, A. Moreno-Salinas ${ }^{1}$, C. M. GamboaAlonso $^{1}$, A. L. De-Leon-lbarra', D. Á. Galarza-Delgado', J. A. Esquivel Valerio'. ${ }^{1}$ Hospital Universitario “Dr. José Eleuterio González”, Servicio de Reumatología, Monterrey, Mexico

Background: Vaccines are one of the safest and effective public health interventions (1). Patients with rheumatic diseases (RD) have a higher risk of morbidity and mortality from vaccine-preventable infections (2). Seasonal Influenza vaccination (SIV) had shown to reduce the incidence, complications, admissions, and mortality from Influenza in patients with RD (3). Vaccine hesitancy is one of the threats to global health established by the $\mathrm{WHO}$.

Objectives: To assess the knowledge and attitudes of rheumatic patients about SIV.

Methods: A self-questionnaire was applied during a community speech for rheumatic patients in October 2019 and also was applied in the rheumatology clinic of the university hospital "Dr. Jose Eleuterio Gonzalez" in Monterrey, Mexico, between November and December 2019. The questionnaire asks age, rheumatic diagnosis, and ten questions. Results are shown in descriptive statistics, the Chisquare and Mann-Whitney $U$ tests were performed to compare groups. A P-value $\leq 0.05$ was considered statistically significant. Analyses were performed using SPSS version 22.0 .

Results: A total of 205 self-questionnaires were applied. $122(59.5 \%)$ in the community speech and $83(40.5 \%)$ in the clinic. The median age was 55 (45.75-62.25) years in the community population and $44(28-59)$ years in the clinic, also the diagnosis distribution was different (Table 1). Most patients considered that rheumatic patients can be vaccinated. About $80 \%$ of patients have ever been vaccinated for seasonal influenza. $87.7 \%$ and $77.1 \%$ considered that SIV is safe and effective. About $85 \%$ of patients considered SIV the best way to avoid complications of Influenza. About $40 \%$ considered not safe to be vaccinated for influenza and other vaccine at the same time. $23.8 \%$ and $48.2 \%$ considered that SIV weakens the immune system and renders it susceptible to infections. Most of the patients know that SIV is free. $23.0 \%$ and $42.2 \%$ consider other measures better than SIV. $17.2 \%$ and $33.7 \%$ considered that SIV will get them worse instead of helping them, and $9.0 \%$ and $14.5 \%$ think that his RD will get worst with SIV.

Table 1. Population Characteristics

\begin{tabular}{lccc}
\hline & $\begin{array}{c}\text { Community } \\
\mathrm{N}=95\end{array}$ & $\begin{array}{c}\text { Clinic } \\
\mathrm{N}=83\end{array}$ & $\mathrm{P}$ \\
\hline Age, years, median (IQR) & $55(45.75-62.25)$ & $44(28-59)$ & $0.001^{*}$ \\
Diagnosis, n (\%) & $67(70.5)$ & $46(55.4)$ & $0.037^{*}$ \\
-RA & $14(14.7)$ & $7(8.4)$ & 0.194 \\
-OA & $3(3.2)$ & $11(13.3)$ & $0.013^{*}$ \\
-SLE & $8(8.4)$ & $8(9.6)$ & 0.780 \\
-Other AID & $3(3.1)$ & $11(13.2)$ & $0.012^{*}$ \\
-Other NAID & & & \\
\hline
\end{tabular}

Conclusion: Misinformation about SIV is patent among rheumatic patients. It is a big challenge to clarify these myths to gain confidence about his safety and effectiveness and provide his benefits.

References:

[1] Hum Vaccin Immunother. 2013;9(8):1774-1778.

[2] Hum Vaccin Immunother. 2018;14(6):1311-1322.

[3] Ann Rheum Dis. 2020;79:39-52

Table 2. Questionnaire

\begin{tabular}{lccccc}
\hline & & Community & Clinic & P \\
& & $N=122(\%)$ & $N=83(\%)$ & \\
\hline 1. Can rheumatology patients be vaccinated? & Yes & $114(93.4)$ & $75(90.4)$ & 0.420 \\
& No & $8(6.6)$ & $8(9.6)$ & \\
2. Have you ever been vaccinated for Influenza? & Yes & $97(79.5)$ & $68(81.9)$ & 0.668 \\
& No & $25(20.5)$ & $15(18.1)$ & \\
3. Influenza vaccine is safe and effective: & Yes & $107(87.7)$ & $64(77.1)$ & $0.045^{*}$ \\
& No & $15(12.3)$ & $19(22.9)$ & \\
4. The best way to avoid compilations of influenza & Yes & $104(85.2)$ & $71(85.5)$ & 0.953 \\
is by using SIV: & No & $18(14.8)$ & $12(14.5)$ & \\
5. It is safe to be vaccinated for Influenza and & Yes & $73(59.8)$ & $48(57.8)$ & 0.774 \\
other vaccines at the same time: & No & $49(40.2)$ & $35(42.2)$ & \\
6. SIV weakens the immune system and renders & Yes & $29(23.8)$ & $40(48.2)$ & $<0.001^{*}$ \\
it susceptible to infections & No & $93(76.2)$ & $43(51.8)$ & \\
7. Do you know that SIV is freely provided? & Yes & $115(94.3)$ & $76(91.6)$ & 0.453 \\
& No & $7(5.7)$ & $7(8.4)$ & \\
8. Herbal medications, traditional medicine and & Yes & $28(23.0)$ & $35(42.2)$ & $0.003^{*}$ \\
some food (like orange) are better than SIV: & No & $94(77.0)$ & $48(57.8)$ & \\
9. SIV instead of helping me will get me worst: & Yes & $21(17.2)$ & $28(33.7)$ & $0.006^{*}$ \\
& No & $101(82.8)$ & $55(66.3)$ & \\
10. SIV will worst my rheumatic disease: & Yes & $11(9.0)$ & $12(14.5)$ & 0.226 \\
& No & $111(91.0)$ & $71(85.5)$ & \\
& & & & &
\end{tabular}

Disclosure of Interests: None declared

DOI: 10.1136/annrheumdis-2020-eular.5074

\section{AB1158 VACCINATION BARRIERS IN PATIENTS WITH RHEUMATIC DISEASES}

G. Figueroa-Parra ${ }^{1}$, A. Moreno-Salinas ${ }^{1}$, L. Santoyo-Fexas ${ }^{1}$, C. M. GamboaAlonso $^{1}$, A. L. De-Leon-lbarra', I. D. J. Hernandez-Galarza', D. Á. GalarzaDelgado', J. A. Esquivel Valerio'. ${ }^{1}$ Hospital Universitario "Dr. José Eleuterio González", Servicio de Reumatología, Monterrey, Mexico

Background: Patients with rheumatic diseases (RD) are at increased risk of infections, attributed to the underlying RD, comorbidities and immunosuppressive therapy, including glucocorticoids, disease-modifying antirheumatic drugs, etc. (1). While many infectious diseases can generally be prevented by vaccines, immunization rates in this specific patient population remain suboptimal (2). Despite being recognized as one of the most successful public health measures, vaccination is perceived as unsafe and unnecessary by a growing number of individuals. Lack of confidence in vaccines is now considered a threat to the success of vaccination programs (3).

Objectives: To describe the main causes of non-vaccination in patients with RD. Methods: A self-questionnaire was applied to a sample of patients with RD in the rheumatology clinic of the university hospital "Dr. Jose Eleuterio Gonzalez" in Monterrey, Mexico between September and December 2019. The questionnaire evaluated demographic characteristics (age, gender, diagnosis) and the vaccination status for Influenza (last year), pneumococcal (last 5 years), Herpes zoster (ever), Human papillomavirus (any dose) and Hepatitis B (any dose). It also includes a question asking: If you didn't receive any of the previous vaccines, what was the reason? (multiple-choice are shown in Table 2). Results are shown in frequencies and percentages. 